\title{
Fracture and fatigue life of Al-based MMCs machined at different conditions
}

\author{
A. Pramanik ${ }^{1 *}$, A. K. Basak ${ }^{2}$ \\ ${ }^{1}$ Department of Mechanical Engineering, Curtin University, Bentley, WA 6102, Australia \\ ${ }^{2}$ Adelaide Microscopy, the University of Adelaide, Adelaide, SA, Australia
}

*Corresponding author, email: alokesh.pramanik@curtin.edu.au, Phone: +61 89266 7981, Fax: +61 89266 2681.

\begin{abstract}
This study investigates fracture and fatigue performance of metal matric composites (MMCs) without any reinforcement and, 0.7 and $13 \mu \mathrm{m}$ particle (10 vol. \%) reinforced which were machined at different feeds and speeds. Fractured surface as well as fatigue generated cracks were investigated in details. The effect of interactions among input machining parameters with their variations on fatigue life has also been analysed. It was found that fatigue cracks don't follow machining traces. Moreover, the cracks are almost straight and sharp when reinforcing particles are smaller but change the course, and surface along the crake is highly damaged when the reinforced particles are bigger. The appearance of fractured surfaces of the samples are very similar regardless of particles size and machining conditions. Though compressive residual stress is generated on the machined MMC surfaces, fatigue life of MMCs are much shorter than that of corresponding matrix material due to the fracture and detachment of reinforcing particles from matrix. Fatigue life has an initial decreasing trend with the rise of feed-rate and then it increases significantly with further increase of feed-rate in the absence of particles machine at low speed. However, fatigue life remains almost constant with the increase of feed-rate for larger particle reinforced MMC machined at high speed. With the increase of speed, opposite trends on fatigue life were noticed for MMCs and matrix material when machined at low and high feeds, respectively. The larger reinforced particles reduces the fatigue life of machined specimens at every interacting combinations of parameters.
\end{abstract}

Key words: MMCs; fracture; fatigue life; machining.

\section{Introduction}

Materials subjected to fluctuating stress fail at much lower stress compared to static fracture stress, which is commonly known as fatigue failure. This fact is particularly imperative during designing aerospace, automobile and biomedical components (Bentley, Mantle et al. 1999, Zhang, Kiat et al. 2009, Pramanik, Zhang et al. 2010). Fatigue failure mechanisms of composite materials is very intricate due to the presence of reinforcements which induce sever anisotropic properties of these materials and failure occur due to matrix cracking, reinforcement breakage and interfacial de-bonding of reinforcing particles. The diverse failure 
modes in addition to inborn anisotropies, complicated stress fields, and non-linear properties of composites restrict the understanding of fatigue properties of metal matrix composites (MMCs) (Basak, Pramanik, \& Islam, 2013; Paknia, Pramanik, Dixit, \& Chattopadhyaya, 2016). Generally, fatigue tests of materials are performed on specimens fabricated with near ideal surface finish such as after polishing which may remove surface defects/inhomogeneity that might reduce the overall fatigue performance (Pramanik, Dixit, et al., 2017). However, from practical applications point of view, it is very expensive as well as difficult to fabricate polished/surface defect free parts towards that. Thus, the effect of machining parameters on fabricated specimens subjected to fatigue is very important (Pramanik, Islam, et al., 2017). The machined specimens have two main features that must be well-defined and controlled: geometric irregularities and metallurgical variations of the surface. This second feature is designated as surface integrity which was usually computed exclusively by surface cracks, but recent investigations widen the perception by all the changes implemented by a machining process such as, residual stress, roughness, hardness and microstructure of the machined surface layers (Abrāo \& Aspinwall, 1996). These represent the quality of the machined surface and subsurface, and become very important towards machined components which endure high static and dynamic stresses (Javidi, Rieger, \& Eichlseder, 2008).

It is reported that particle size, particle content and matrix aging states considerably influence particle fracture rate in MMCs under cyclic loading. Reinforced particles affect the threshold levels and fatigue crack growth rates in A1-SiCp MMCs which is partly arouse due to crack closure, defection and trapping; and to some extent, crack bridging (Kumai, King, \& Knott, 1990; Shang, Yu, \& Ritchie, 1988; Sugimura \& Suresh, 1992). As fatigue crack propagates, particle fracture delicately rests on maximum stress intensity. The occurrence of particle fracture is usually insignificant at smaller crack sizes but it rises with the rise of maximum stress intensity and becomes constant during fast fracture (Kumai et al., 1990; Shang et al., 1988; Sugimura \& Suresh, 1992). Li et al., (Li, Liang, Chen, Zhu, \& Chen, 2014) mentioned that smaller SiC particles (4.5 $\mu \mathrm{m})$ displayed higher resistance to fatigue crack compare to the composite with $20 \mu \mathrm{m} \mathrm{SiC} \mathrm{particles} \mathrm{and}$ unreinforced alloy. The crack in $4.5 \mu \mathrm{m}$ reinforced $\mathrm{SiC}$ particles induced higher level of fatigue crack closure which reduce crack growth. Shang et al. (Shang et al., 1988) found that aluminium matrix composites with larger sized reinforcements fracture preferentially at low stress intensity variation. Similarly, Kumai et al. (Kumai et al., 1990) reported that larger particles had a greater propensity for fracture in 6061 alloy reinforced with SiC particles. Sugimura and Suresh (Sugimura \& Suresh, 1992) noticed that the probability of particle fracture rises with the rise of reinforcement volume fraction in fatigue crack growth in cast $\mathrm{A} 1-3.5 \% \mathrm{Cu}$ reinforced with varying volume fractions of $\mathrm{SiC}$ particles. This behaviour was attributed to higher restraint levels of matrix together with higher volume content of reinforcing particles. Arsenault et al. (Arsenault, Wang, \& Feng, 1991) found that underage material had a greater propensity of particle fracture than that of overaged microstructure because of lower matrix fracture strain in later material. Luk et al., (Luk et al., 2015) noticed that low cycle fatigue life of SiC particle reinforced 2009 aluminium alloy composites was equivalent 
within experimental scatter in both T4 and T6 conditions. While investigating the influences of particle size, volume fraction and matrix strength collectively on stress-controlled fatigue life and particle fracture during fatigue crack growth in $\mathrm{SiC}$ particle reinforced 2124 aluminium alloy, Hall et al., (Hall, Jones, \& Sachdev, 1994) found that the strength and fatigue life of MMCs rise with the reduction of particle size and increase of volume content of reinforcing particles. The particle fracture incidents raised with the rise of reinforcement size and content, crack tip stress intensity and matrix strength.

Fatigue crack nucleation and transmission can be attributed to surface integrity in most cases. Reed and Viens reported (Reed \& Viens, 1960) a correlation between surface residual stresses and apparent fatigue limit of titanium, that is, tensile residual stresses decreased the fatigue strength and compressive residual stresses increased it. This correlation was later confirmed by Koster et al., (Koster, 1970) for Ti-6A1-4V where the specimens were fabricated by grinding and shaping and, as machined samples exhibit higher fatigue strength than stress-relieved samples with identical surface topography. Matsumoto et al., (Matsumoto, Magda, Hoeppner, \& Kim, 1991) studied the effect of fly cutting and grinding on the fatigue strength of hardened AISI 4340 steel in tension under load control. Compressive residual stress were generated all the cases though the stresses penetrated deeper when the fly cutter was used. Therefore, fly cutting induced higher fatigue strength than that of grinding. Sharman et al., (Sharman, Aspinwall, Dewes, Clifton, \& Bowen, 2001) noticed higher tension-tension fatigue strength (475MPa) in turned $\mathrm{Ti}-45 \mathrm{Al}-2 \mathrm{Nb}-2 \mathrm{Mn}+0.8 \mathrm{vol} \% \mathrm{TiB} 2$ alloy compare to that of electro-chemical machined and electro-discharge textured samples. This was due to higher compressive surface residual stresses generated during turning the workpiece material.

It is well known that cracks due to fatigue usually start from free surface (Li et al., 2014) as it undergoes maximum loading and thus the free surfaces generated from diverse machining processes show wide range of fatigue behaviour (Zlatin and Field 1973). Therefore, machining induced residual stresses, surface morphology microstructure (phases, plastic deformation, tears, voids, pits, burrs, cracks etc.), microhardness and notch-like surface irregularities affect the fatigue strength significantly (Dieter, 2015). In addition, machined surfaces became work-hardened severely and contain micro-cracks which eventually affect the fatigue behaviour of specimens. Taylor and Clancy (Taylor \& Clancy, 1991) explored high-cycle fatigue behaviour of En19 steel specimens fabricated by polishing, grinding, milling and subsequent heat treatment to eliminate residual stress. The fatigue limit data were presented as a function of roughness through Kitagawatype charts. It was reported that the fracture mechanics methods are beneficial for comparatively low roughness, when the surfaces can be modelled as a series of short cracks. A notch-based methodology is more suitable for higher roughness.

Probabilistic terms are used to represent the fatigue performance of mechanical components because of stochastic nature of this parameter. As evident in literature, wider deviation in fatigue results are presented in many investigations (typically 20\%) for same $R a$ value and this demands the relevance of relying merely on surface roughness $R a$. Novovic et al., (Novovic, Dewes, Aspinwall, Voice, \& Bowen, 2004) studied effect of 
surface topography/integrity generated from traditional and non-traditional machining on the fatigue performance based on data available in literature. It was noted that lower roughness gave longer fatigue life, but fatigue life was dependent on workpiece residual stress and surface microstructure, rather than roughness when roughness $(\mathrm{Ra})$ in the range $2.5-5 \mu \mathrm{m} \mathrm{Ra}$. machined surface roughness in excess of $0.1 \mu \mathrm{m}$ Ra has a strong influence on fatigue life when there was no residual stress. Bayomi and Abd El-Latif (Bayoumi \& Abdellatif, 1995) correlated different surface roughness parameters with fatigue endurance limit of an aluminium alloy where $R a$ and $R q$, rather than spatial parameters have noticeable effect on endurance limit. Residual stress in the surface is often a superior indicator of fatigue behaviour than surface topography when the range surface roughness, $R a$ is $2.5-5 \mu \mathrm{m}$. Pramanik et al., (Pramanik, Basak, Islam, \& Littlefair, 2015) reported that non-traditional machining methods such as, electrical discharge machining on MMCs have varied effect on workpiece surface integrity and therefore fatigue performance depends on the material removal mechanism.

An extensive review of literature indicates that the research on the effect of machining parameters on fatigue behaviour of materials is still at early stage. Fatigue strength of machined components depends on workpiece material, machining type and conditions. So far, the information on this area is available only for very few alloys such as, titanium, steel, aluminium and nickel alloys which include few isolated machining parameters as reviewed by Hakami et al., (Hakami, Pramanik, \& Basak, 2016) and Pramanik et al.(Pramanik, Dixit, et al., 2017). Pramanik et al., (Pramanik, Islam, et al., 2017) investigated the contribution of different parameters on fatigue life of machined MMC components. As per their findings, the interacting effects of particle size/feed and particles size/speed considerably affect the fatigue life of machined MMC components. The combined effect of these contributions is much more pronounced than the summation of individual contributions of specific parameters due to synergy effect. Therefore, the modelling of fatigue life based on particle size, machining speed and feed becomes very complex. Larger particles and lower feeds induce more defects on machined MMC surfaces while the speed does not have a noticeable effect. Therefore, fatigue life increases with the decrease in particle size and increase in feed. However, fatigue life does not change with speed variation. The propagation of fatigue cracks is arrested or deflected by reinforcing particles. The larger particles possess a higher capability to stop crack propagation. Therefore, machined MMC specimens reinforced with smaller or without any particles often separated completely as opposed to the counterparts containing larger reinforcing particles (Pramanik, Islam, et al., 2017).

Having said that, there is no details information on synergized interactions of interacting machining parameters on fatigue behaviour such as, fatigue life, crack propagation and fractured surface of MMCs though these materials are emerged as an important candidate for many high performance applications. In view of that, the objective of the present study is to investigate the effect of interacting machining parameters on flexural fatigue behaviour of MMCs reinforced with different reinforcement sizes. The results will benefit 
researchers as well professionals to increase the understanding of fatigue behaviour of MMC parts produced by machining.

\section{Material and methodology}

Two different types of MMCs were investigated in this study, namely: $0.7 \mu \mathrm{m}$ and $13 \mu \mathrm{m} \mathrm{SiC} \mathrm{(10} \mathrm{vol.} \mathrm{\% )}$ reinforced 6061 aluminum matrix composite. The MMC slabs was obtained through in-situ casting technique followed by hot-isostatic pressing and acquired commercially from Aerospace Metal Composites Limited, UK. These slabs were used as feedstock materials to fabricate specimens for flexural fatigue testing with the help of milling and drilling, which was carried out on a Leadwell V-30" CNC machine with the help of K10 cemented carbide tools. In addition to that, pure 6061 aluminum alloy (cast slab) was used as benchmark material which was obtained from the same source and under similar process condition. The SEM micrograph of as received MMC with $13 \mu \mathrm{m}$ reinforcement, after standard metallographic polishing, together with respective EDX spectra in matrix material are given in figure 1. The 6061 aluminum alloy contains 98.5, 0.7, 0.6 and 0.2 wt. \% Al, $\mathrm{Mg}$, Si and $\mathrm{Cu}$ respectively. Final flat dog-bone shaped specimen with neck radius of $75 \mathrm{~mm}$ and an overall length and width of $145 \mathrm{~mm}$ and $40 \mathrm{~mm}$ respectively was used as shown in figure 2. The variation of machining parameters and materials is summarized in table 1 . A sufficient size hole $(8 \mathrm{~mm})$ was drilled through the center of the specimen to ensure stress concentration to be controlled and confined fatigue failure to propagate around that area (Callister (2010).

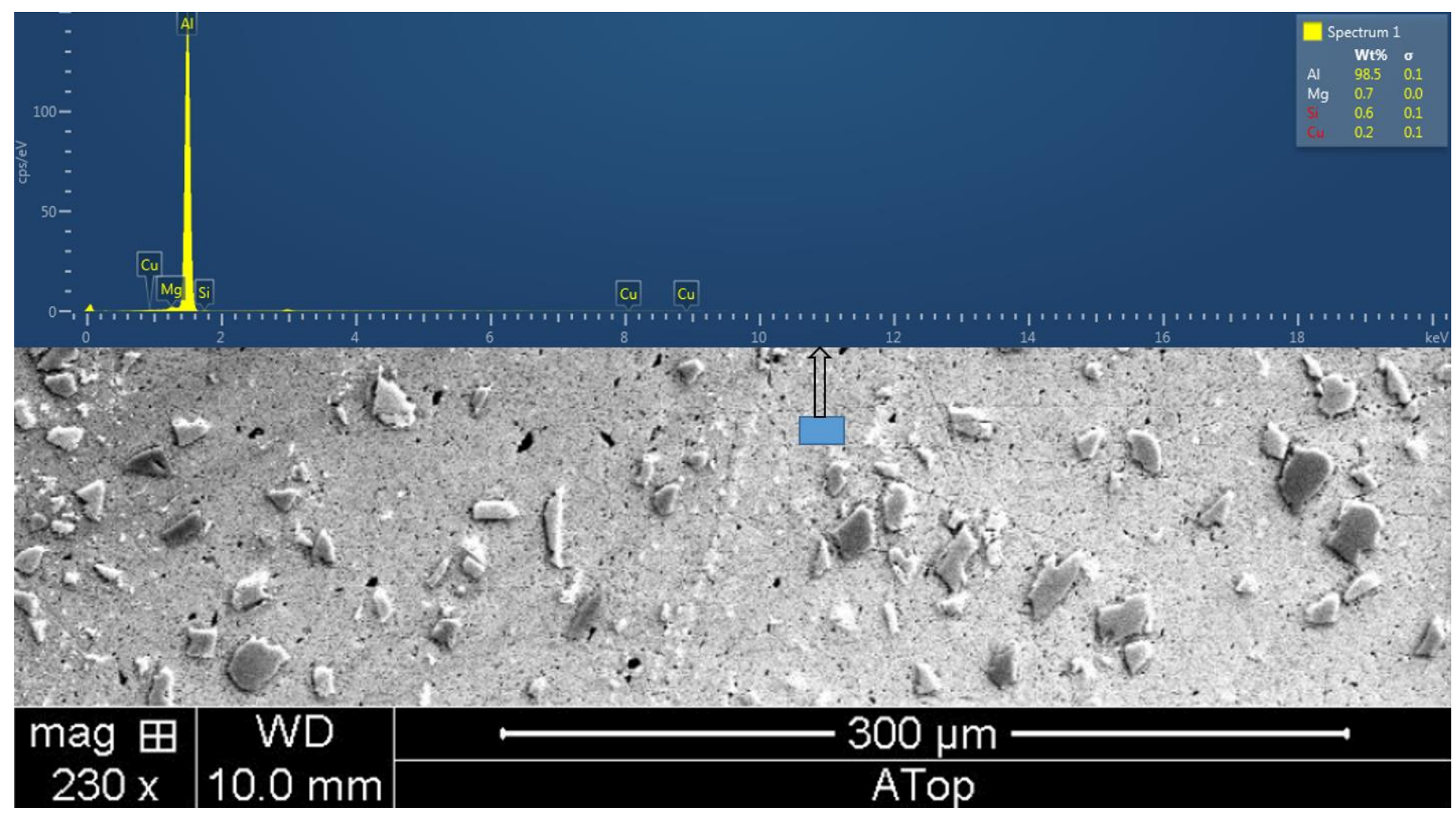

Figure 1: SEM micrograph of as received MMC $(13 \mu \mathrm{m} \mathrm{SiC})$ and EDX spectra in matrix material. 


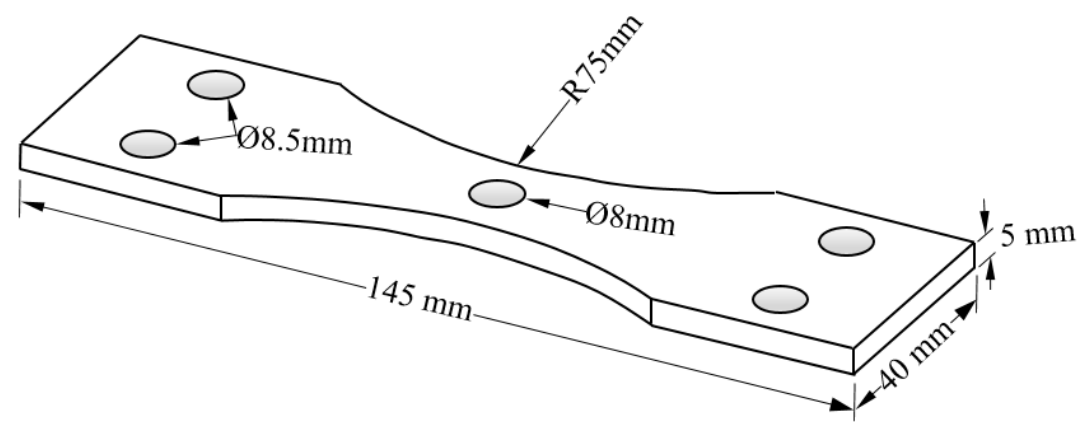

Figure 2: Schematic of flat dog-bone specimen for flexural fatigue test.

Table 1: Milling and drilling parameters used to fabricate test specimens.

\begin{tabular}{|c|c|c|c|c|}
\hline Experiments & $\begin{array}{l}\text { Milling feed } \\
\text { rate }(\mathrm{mm} / \mathrm{rev})\end{array}$ & $\begin{array}{l}\text { Drilling feed } \\
\text { rate }(\mathrm{mm} / \mathrm{rev})\end{array}$ & $\begin{array}{l}\text { Cutting speed } \\
\qquad(\mathrm{m} / \mathrm{min})\end{array}$ & $\begin{array}{c}\text { Reinforcement } \\
\text { size }(\mu \mathrm{m})\end{array}$ \\
\hline 1 & 0.05 & 0.01 & 20 & \multirow{6}{*}{13} \\
\hline 2 & 0.35 & 0.03 & 20 & \\
\hline 3 & 0.35 & 0.03 & 60 & \\
\hline 4 & 0.05 & 0.01 & 100 & \\
\hline 5 & 0.15 & 0.02 & 100 & \\
\hline 6 & 0.35 & 0.03 & 100 & \\
\hline 7 & 0.05 & 0.01 & 20 & \multirow{2}{*}{0.7} \\
\hline 8 & 0.35 & 0.03 & 100 & \\
\hline 9 & 0.05 & 0.01 & 20 & \multirow{6}{*}{0} \\
\hline 10 & 0.15 & 0.02 & 20 & \\
\hline 11 & 0.35 & 0.03 & 20 & \\
\hline 12 & 0.05 & 0.01 & 60 & \\
\hline 13 & 0.05 & 0.01 & 100 & \\
\hline 14 & 0.35 & 0.03 & 100 & \\
\hline
\end{tabular}

The tool paths in course of specimen fabrication are outlined in figure 3. Both peripheral and axial milling operations were performed on the specimens to remove excess material. Drilling was performed using the same milling tool to make $8 \mathrm{~mm}$ diameter hole in the center of the neck area of the specimen. The reverse cycle fatigue test was performed on Schenck flexural fatigue machine. Each specimen was tested at displacement amplitude of $0.58 \mathrm{~mm}$ under constant rotational speed of $1500 \mathrm{rpm}$. In the case where the specimens did not fail, the machine would be stopped at $1 \times 10^{6}$ cycles. Otherwise, the machine stops when the sample fails regardless of complete or partial separations of samples. Every experiment was repeated three times. Topography of the fractured surfaces were investigated with the help of optical microscope as well as field emission scanning electron microscope (Quanta 450 FE-SEM, FEI). The surface roughness was measured using Mitutovo Surftest SJ-201P profilometer. 


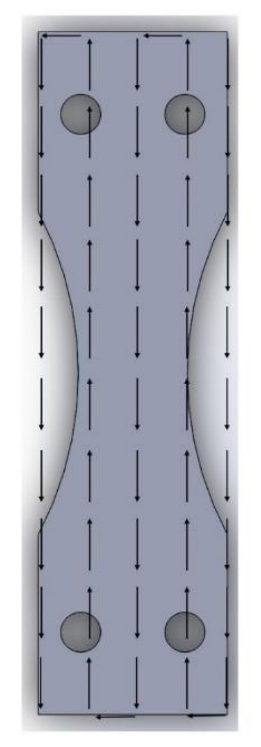

Operation 1

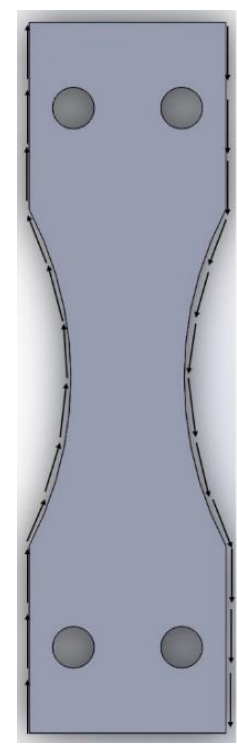

Operation 2

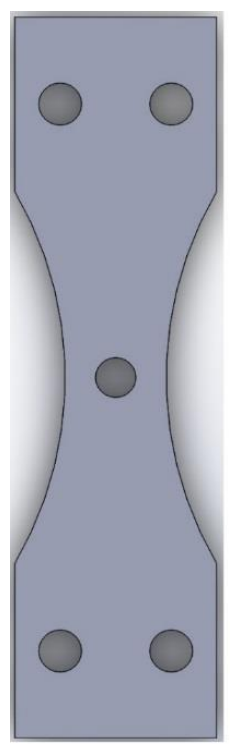

Operation 3

Figure 3: Schematic of tool path operation towards specimen fabrication.

Interactions between different machining parameters (Table 1) have significant effect on the surface integrity of the machined parts (Islam, Anggono, Pramanik, \& Boswell, 2013; Islam, Boswell, \& Pramanik, 2013; Islam \& Pramanik, 2015). Therefore, in order to include this effect in our analysis different parameters at 'high' and 'low' values have been discussed as follows: 'low' values indicate the lower magnitude of parameters such as, no particles, $20 \mathrm{~m} / \mathrm{min}$ speed, $0.05 \mathrm{~mm} / \mathrm{rev}$ milling feed and $0.001 \mathrm{~mm} / \mathrm{rev}$ for drilling feed. Similarly, 'high' indicate the higher magnitude of parameters such as, $13 \mu \mathrm{m}$ particles, $100 \mathrm{~m} / \mathrm{min}$ speed and $0.35 \mathrm{~mm} / \mathrm{rev}$ milling feed and $0.03 \mathrm{~mm} / \mathrm{rev}$ drilling feed. In this case, there is no variation of milling feed with respect to drilling feed, but the feeds of these two processes vary simultaneously. As drilling and milling are two different processes, therefore it is not realistic to have same feed rate for both of them. Thus, values of feed rates of these two processes are different. However, a consistency was maintain in all experiments, as described hereafter. When the milling feed rate was $0.05 \mathrm{~mm} / \mathrm{rev}$, the drilling feed rate was maintained at $0.01 \mathrm{~mm} / \mathrm{rev}$; when the milling feed rate was $0.15 \mathrm{~mm} / \mathrm{rev}$, drilling feed rate was $0.02 \mathrm{~mm} / \mathrm{rev}$ and finally when the milling feed rate was $0.35 \mathrm{~mm} / \mathrm{rev}$, drilling feed rate was $0.03 \mathrm{~mm} / \mathrm{rev}$. In any case, for a constant milling feed rate, drilling feed was also constant to a value corresponding to milling feed rate. Thus, when the results of experiments 2, 3 and 8 are compared it shows the effect of speed which varies as 20,60 and $100 \mathrm{~m} / \mathrm{min}$. In this case, reinforcement size and feed rates of milling and drilling processes remain constant at higher values at $13 \mu \mathrm{m}, 0.35 \mathrm{~mm} / \mathrm{rev}$ and $0.02 \mathrm{~mm} / \mathrm{rev}$, respectively. The effect of other input parameters were also investigated in the similar way.

\section{Results}

\subsection{Nature of failure}


On the completion of fatigue test, visual check on specimens were carried out and consolidated in figure 4 for comparison purpose. Irrespective of specimens, initial observation is that, fatigue crack starts at the edge of the drilled hole on flat surface which was intended. After crack initiation, it starts to propagate along flat surface as well as along the depth of drilled hole. The failure due to fatigue occurs along transverse axis of the specimens. Crack propagation length in transverse direction is longer than that in depth direction and in many cases, cracks crosses longer longitudinal length but doesn't cross thickness of shorter depth. In most of the cases, cracks crossed the drilled hole along its diameter (i.e., through hole-centre). However, in one case, crack obviously neither crossed the drilled hole along its diameter nor went through the hole-centre when the material was reinforced with $13 \mu \mathrm{m}$ particles and machined at lower speed and feed, as shown in Figure 4(o). Complete fracture separation occurs for specimens without reinforcements at all conditions (except the specimens machined at a higher speed of $100 \mathrm{~m} / \mathrm{min}$ ) and low feeds of $0.05 \mathrm{~mm} / \mathrm{rev}$ in milling. When the reinforcing particle size is $0.7 \mu \mathrm{m}$, a complete separation of specimens takes place only when those were machined at a higher speed of $100 \mathrm{~m} / \mathrm{min}$ and higher feed of $0.35 \mathrm{~mm} / \mathrm{rev}$. In the case of MMCs reinforced with $13 \mu \mathrm{m}$ particles, complete separation of specimens occurs only when those were machined at higher speed of $100 \mathrm{~m} / \mathrm{min}$ and lower feeds of $0.05 \mathrm{~mm} / \mathrm{rev}$ in milling and a lower speed of $20 \mathrm{~m} / \mathrm{min}$ and higher feeds of $0.35 \mathrm{~mm} / \mathrm{rev}$.

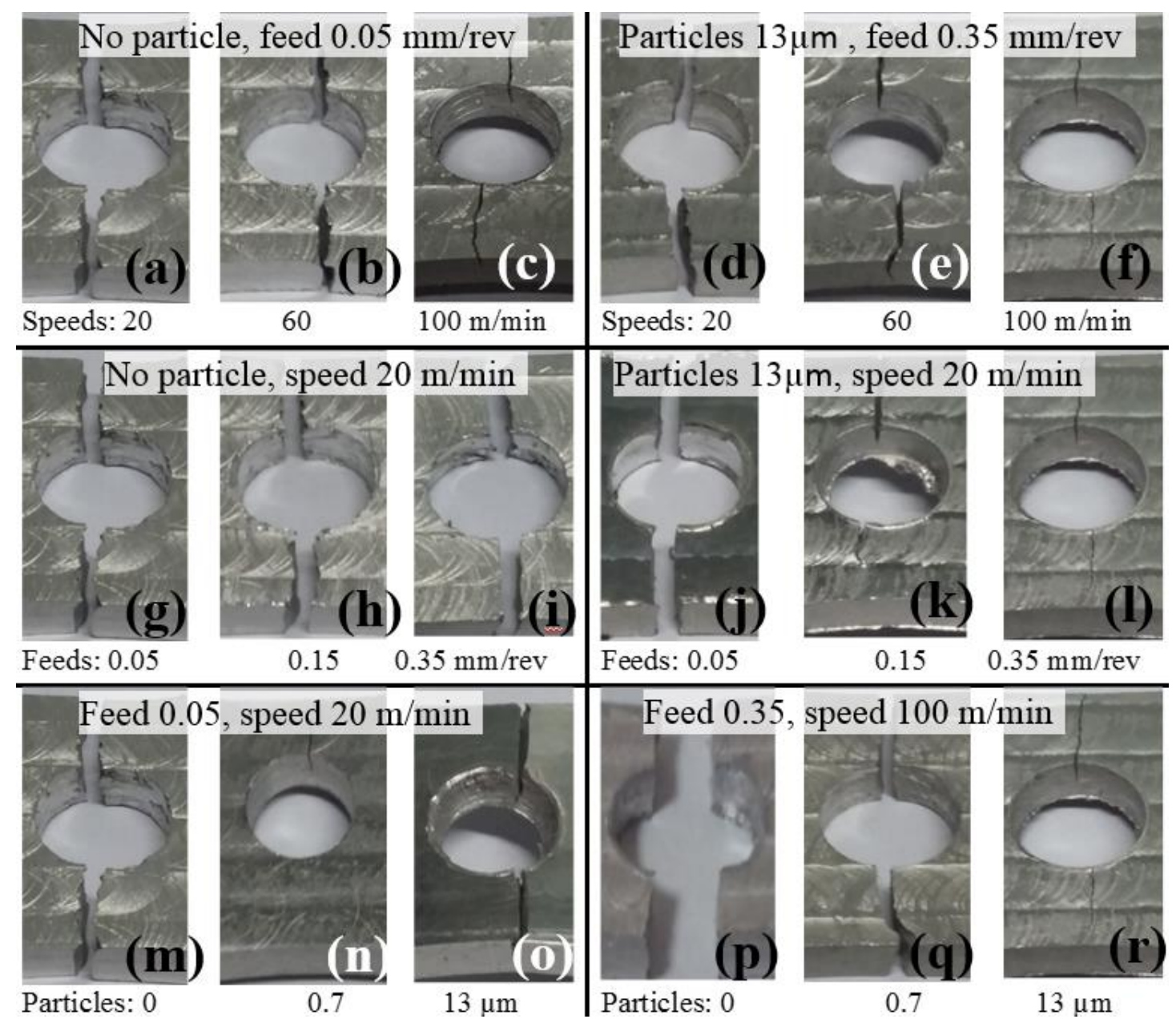


Fig. 4: Appearance of fatigue cracks /fracture on specimens fabricated through different machining parameters (each hole is of $8 \mathrm{~mm}$ diameter) and subjected to flexural fatigue testing (Pramanik, Islam, et al., 2017).

The initiation of crack at the edge of central holes indicate that, states of milled flat surfaces and drilled cylindrical surfaces influence its origin. For the convenience of analysis, speeds and feeds of drilling didn't vary with respect to that of milling in this investigation. Certain feed and speed during drilling were allocated for a specified feed and speed, respectively during milling. This means, when it is mentioned that surface was generated from milling at feed $0.05 \mathrm{~mm} / \mathrm{rev}$ and speed $100 \mathrm{~m} / \mathrm{min}$, then it should be considered that the surface of the drilling hole was generated at feed $0.01 \mathrm{~mm} / \mathrm{rev}$ and speed $100 \mathrm{~m} / \mathrm{min}$. A comparison of fractured surfaces in terms of factography are presented in figure 5 in cases where complete separation occurred.

The surfaces are very similar regardless of machining conditions and reinforcement size. Fracture mode is predominantly ductile with the presence of microscopic cracks in matrix coupled with particulate failure both by cracking and debonding at particle-matrix interfaces (indicated by arrows in figure 5). Presence of voids and dimples are characteristic features of ductile fracture that are present all over the fracture surfaces. The failure start with the initiation of microscopic cracks that are essentially featureless. When the crack tip obstructed by $\mathrm{SiC}$ particles, number of scenarios can takes place depending on state of stress in that particular region such as, fracture of $\mathrm{SiC}$ particles, arbitrarily scattered microscopic voids, ductile tear ridges, isolated pouches of fine and shallow patterns or wrinkles, etc. The general observation is that, obvious cracks are present in the MMCs reinforced with bigger particles and finer cracks are noticed in the surface of matrix material and MMC reinforced with smaller particles (Fig. 5). Fractured and pulled out particles were noted in only for MMCs with $13 \mu \mathrm{m}$ particles (Fig. $5 \mathrm{~b}$ and c) however cleavage steps and ductile tearing ridges were clearly visible regardless of experiment conditions. The size of the dimples of the surface of cleavage fracture did not change with varied machining parameters and reinforcement size or absence of reinforcements particles for the series of variables considered in this study. 


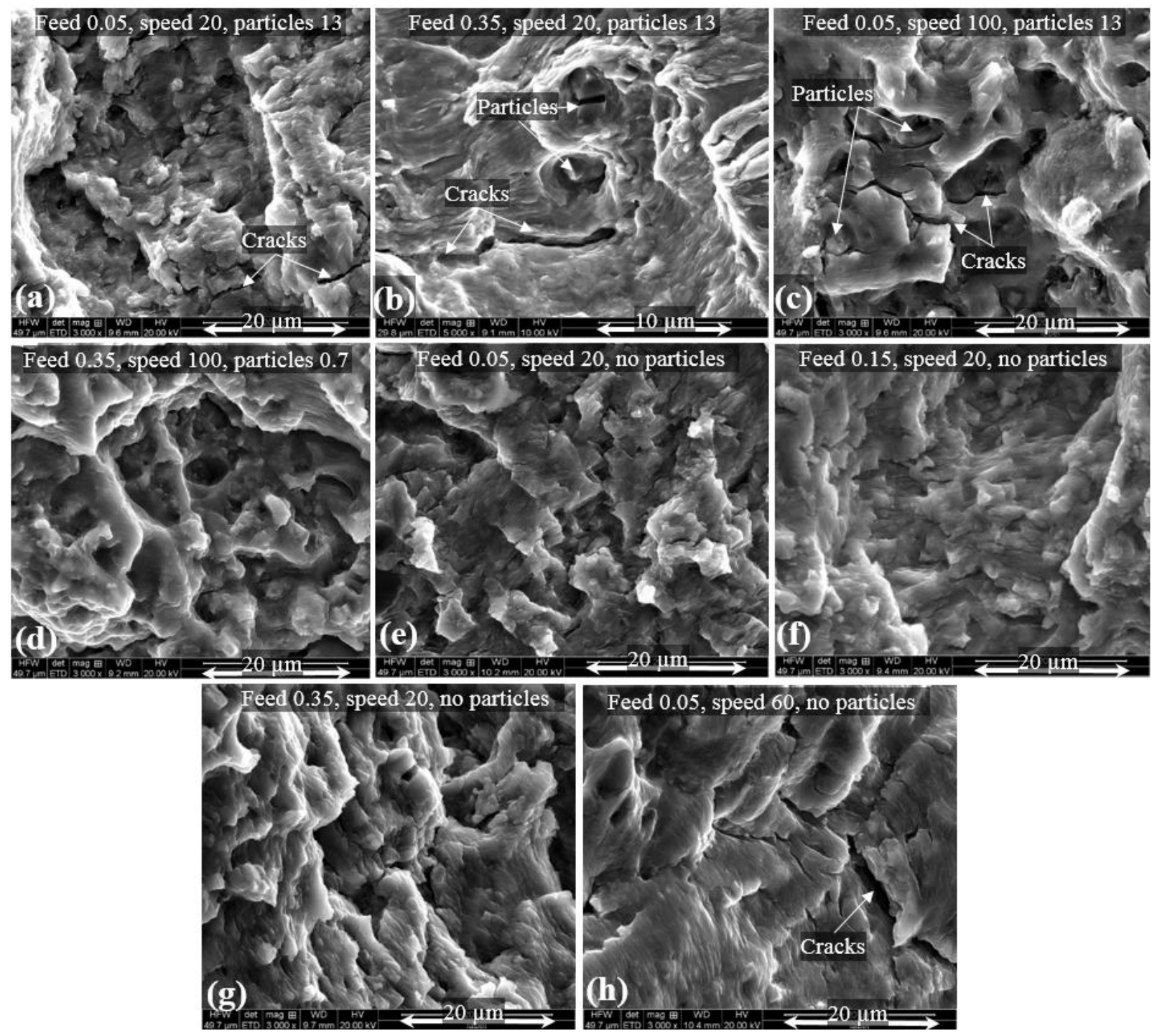

Fig. 5: SEM images on fractured sample surfaces after flexural fatigue testing on specimens fabricate at different machining conditions.

The area of changeover from stable microscopic to fast unsteady microscopic crack growth and ultimate failure of test specimen is obvious as shown in figure 5: (a) fine microscopic cracks in matrix, (b) cracking and debonding of $\mathrm{SiC}$ particles and (c) ductile tear ridges. In addition to that, microscopic striations are evident in figure 6, together with microscopic voids of submicron scale to tens of microns are present. The sources of macroscopic voids and resultant shallow dimples are critical events that control fracture (Ceschini, Minak, \& Morri, 2006). The restraints induced by the hard and brittle SiC particles in ductile and soft metal matrix affect cyclic stress response of the composite due to the fully reversed stressing and favours limited void growth (Srivatsan \& Al-Hajri, 2002). The observed failure at the interface is the result of two simultaneous processes. Firstly, Von-Mises stress is larger at a slight distance from particle-matrix interface than that at interface (Tirosh, Katz, Lifschuetz, \& Tetelman, 1979) as local plastic strain near interface area is usually three times the far-field applied strain (Orr \& Brown, 1974). At the later phases of deformation, tiny cracks initiate and propagate in this area of high plasticity assisted by local raise of hydrostatic stresses as a result of the existence of coarse SiC particles (Karlak, Crossman, Grant, Fleck, \& Mehan, 1974). This puts forward the 
vital role played by local plastic strains on damage commencement and propagation in the composite microstructure (Srivatsan \& Al-Hajri, 2002).

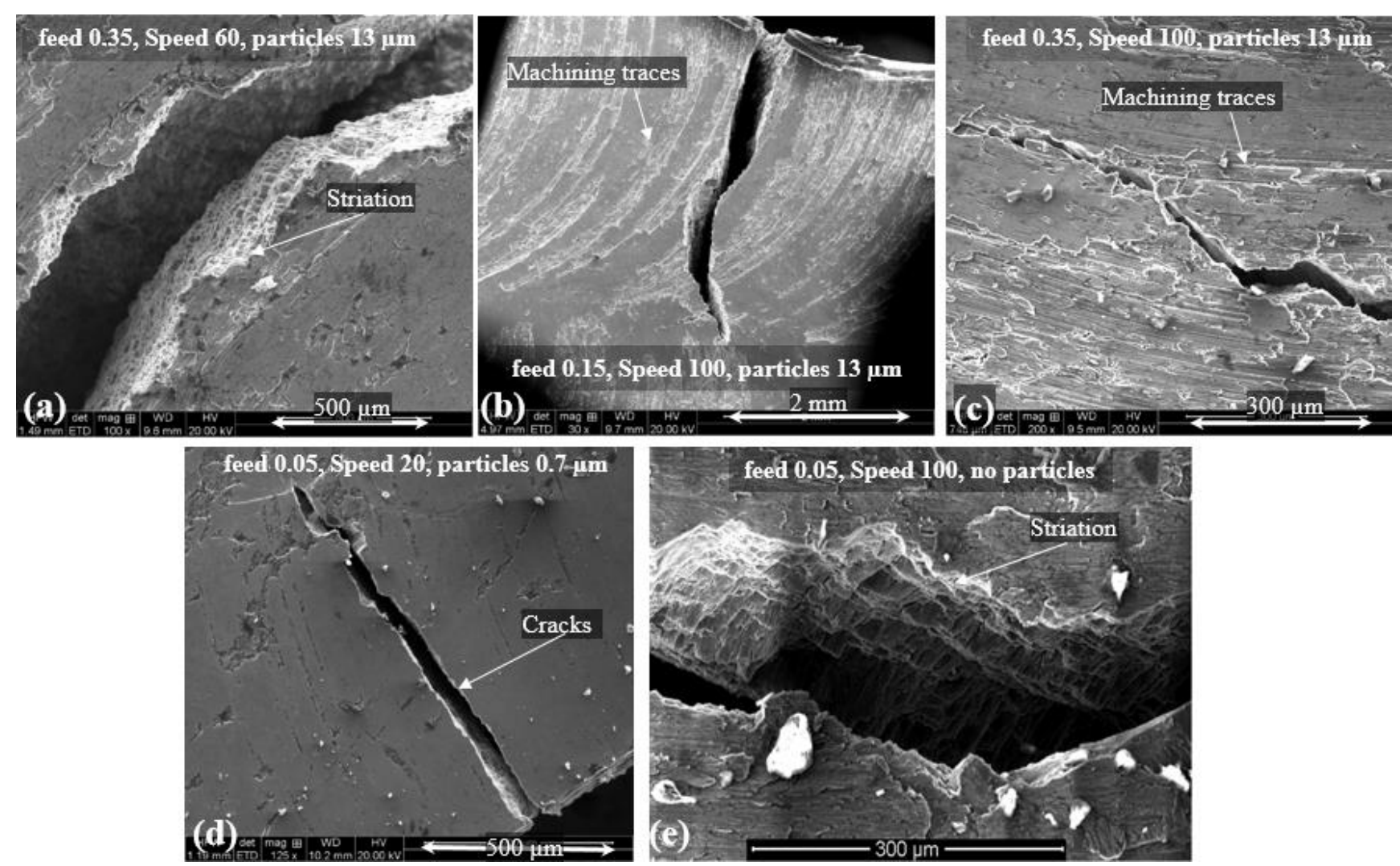

Fig. 6: Appearance of cracks on specimens after fatigue tests in the case of incomplete separation.

The geometry of cracks present in different specimens after fatigue test on specimens fabricated at different machining conditions are shown in figure 6 in the cases of incomplete separation. In this figure, the machining traces are clearly visible alongside cracks. However, it is interesting to observe that, cracks did not follow the machining traces and propagate parallel as well as across the machining traces. Cracks in MMC reinforced with $0.7 \mu \mathrm{m}$ particles are straight but in other materials the directions of crack propagation vary along its course.

An extensive investigation on the nature of crack tip appearance in MMCs reinforced with $13 \mu \mathrm{m}$ reinforcements are presented in figure 7 . In this case, crack tip is not very sharp and ended up with multiple cracks and take the shape of spikes. These spikes are generated due to elongation of the material during crack propagation mostly due to void formation around reinforcing particulates. Details of crack tip in MMCs reinforced with $0.7 \mu \mathrm{m}$ are presented in figure 8 . The crack line is clean and sharp with very minor damage of sounding surfaces and ends as a curved edge. 

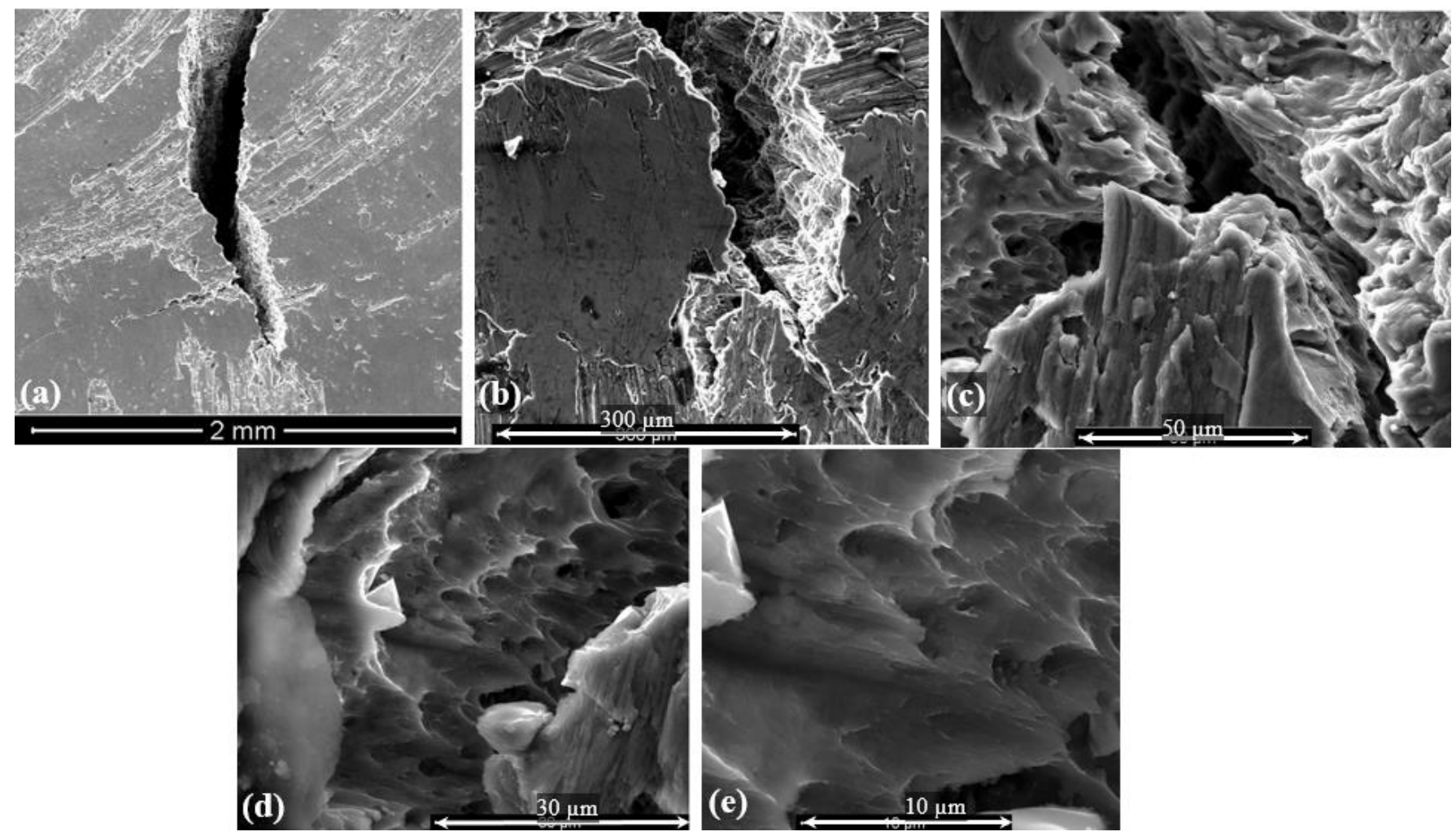

Fig. 7: Details of the formation of crack tips on specimens after fatigue test (experiment 5) on samples milled at $0.15 \mathrm{~mm} / \mathrm{rev}$ feed (medium value), $100 \mathrm{~m} / \mathrm{min}$ speed (high value) with $13 \mu \mathrm{m}$ particle (high value) reinforced MMCs.
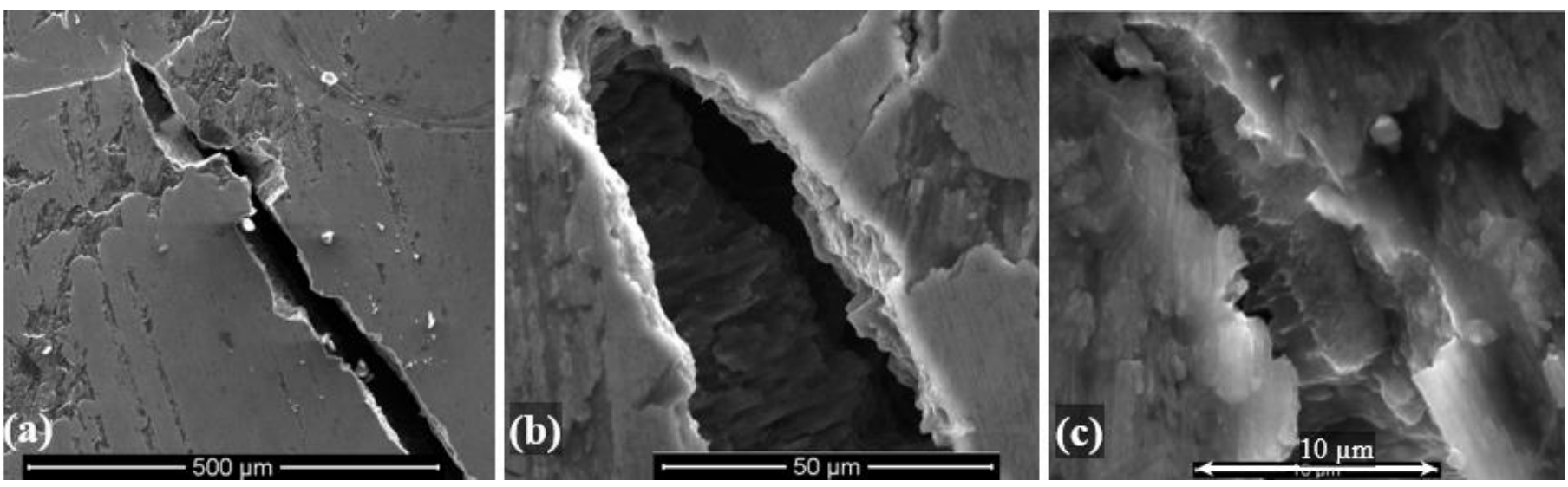

Fig. 8: Details of formation of crack tips on specimens after fatigue test on samples milled at $0.05 \mathrm{~mm} / \mathrm{rev}$ feed, $20 \mathrm{~m} / \mathrm{min}$ speed with $0.7 \mu \mathrm{m}$ particle reinforced MMCs.

\subsection{Surface roughness}

The influence of surface roughness on fatigue life is well known though its only notable above certain value of surface roughness (Bayoumi \& Abdellatif, 1995). In this investigation, influence of individual machining parameters as well as their interactions with surface roughness have been analyzed. While investigating the effect of drilling feed on surface roughness, other parameters, i.e. speed and size of reinforcements were kept constant at low values (speed: $20 \mathrm{~m} / \mathrm{min}$ and reinforcement 0 , i.e., no particle) as well as high values (speed: $100 \mathrm{~m} / \mathrm{min}$ and particles: $13 \mu \mathrm{m}$ ). The influence of feed on surface roughness at low and high values of 
constant parameters are presented in figure 9. It seems that surface roughness rises with the rise of feed when the fixed/constant parameters are of high values. On the other hand, surface roughness decreases initially with the increase of feed but the roughness decreases with further rise when the constant parameters are of low values. The surface roughness at low values of constant parameters is always bigger than that at high values of constant parameters.

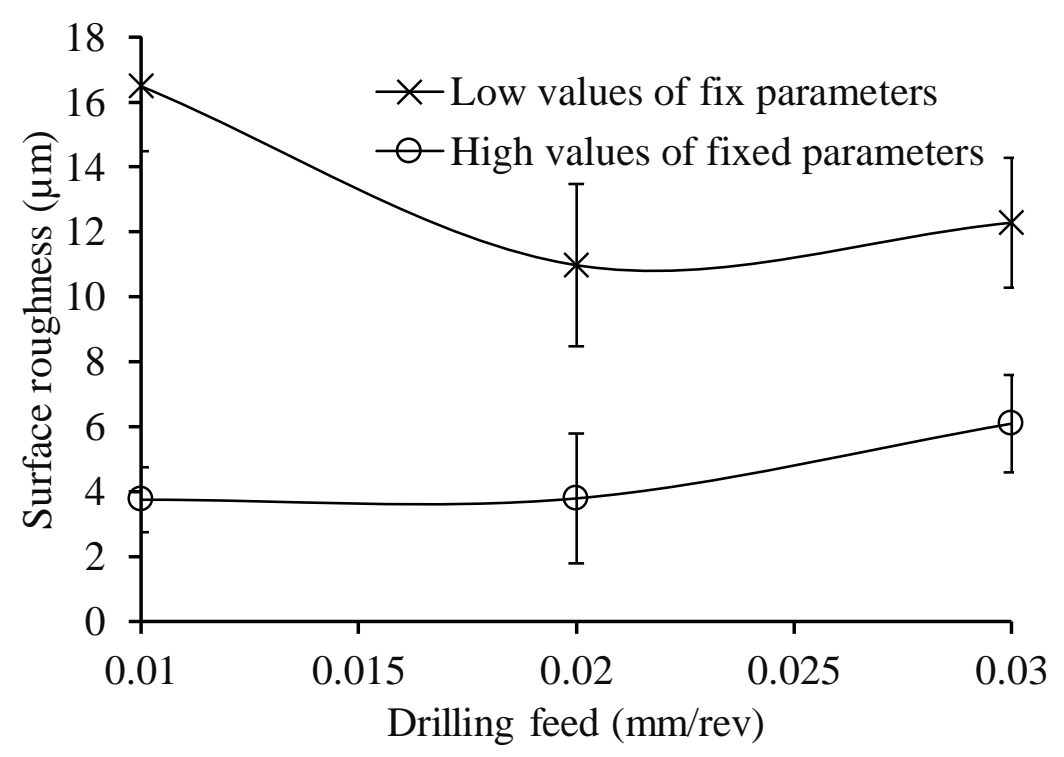

Fig. 9: Effect of feed on surface roughness (on the central hole).

The influence of machining speed on surface roughness at low (feed: $0.01 \mathrm{~mm} / \mathrm{rev}$ and reinforcement 0 , i.e., no particle) and high (feed: $0.03 \mathrm{~mm} / \mathrm{rev}$ and particles: $13 \mu \mathrm{m}$ ) values of constant parameters are presented in figure 10. The figure shows that, surface roughness reduces slightly with the rise of speed when the fixed/constant parameters are of high values. However, surface roughness reduces significantly with the rise of speed when the constant parameters are of low values. Surface roughness at low values of constant parameters is always bigger than that at high values of constant parameters except when the speed is 100 $\mathrm{m} / \mathrm{min}$.

The influence of particle size on surface roughness at low (feed: $0.01 \mathrm{~mm} / \mathrm{rev}$ and speed $20 \mathrm{~m} / \mathrm{min}$ ) and high (feed: $0.03 \mathrm{~mm} / \mathrm{rev}$ and speed $100 \mathrm{~m} / \mathrm{min}$ ) values of constant parameters are presented in figure 11 . The figure indicates that surface roughness decreases slightly and then remains constant with the rise of speed when the fixed/constant parameters are of high values. In contrast, surface roughness decreases significantly with the addition of $0.7 \mu \mathrm{m}$ particles in the matrix, however, with the increase of reinforcement size to $13 \mu \mathrm{m}$, surface roughness increased significantly when the constant parameters are of low values. Surface roughness at low values of constant parameters is always bigger than that at high values of constant parameters except when the reinforcing particle size is $0.7 \mu \mathrm{m}$. 


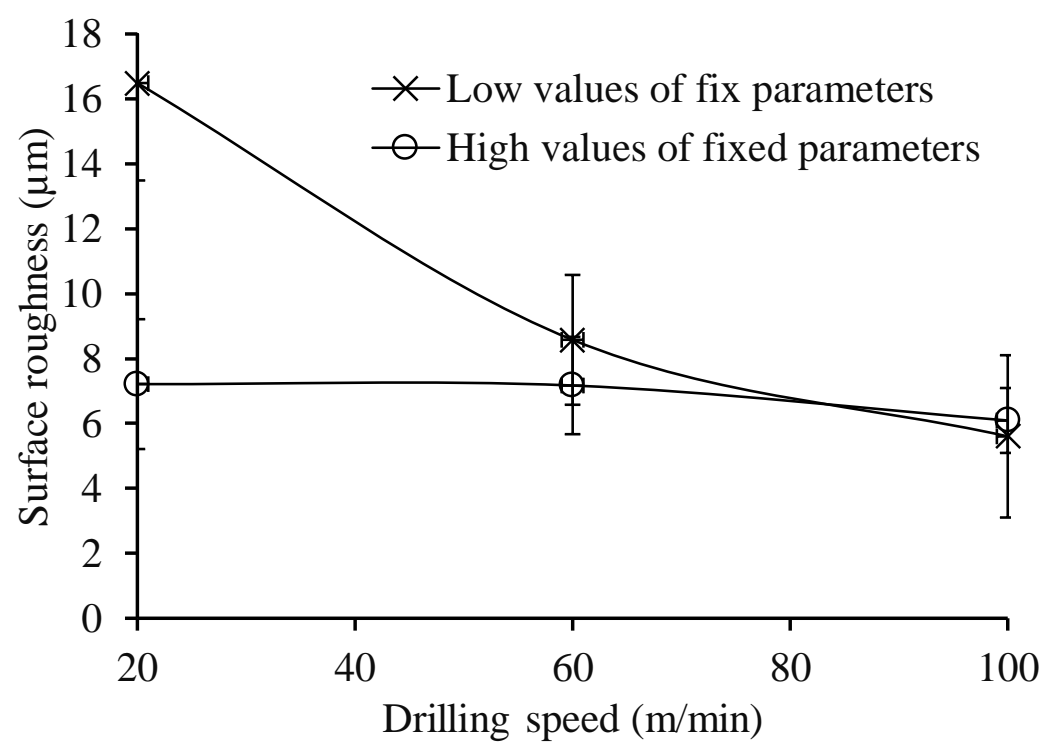

Fig. 10: Effect of speed on surface roughness (on the central hole).

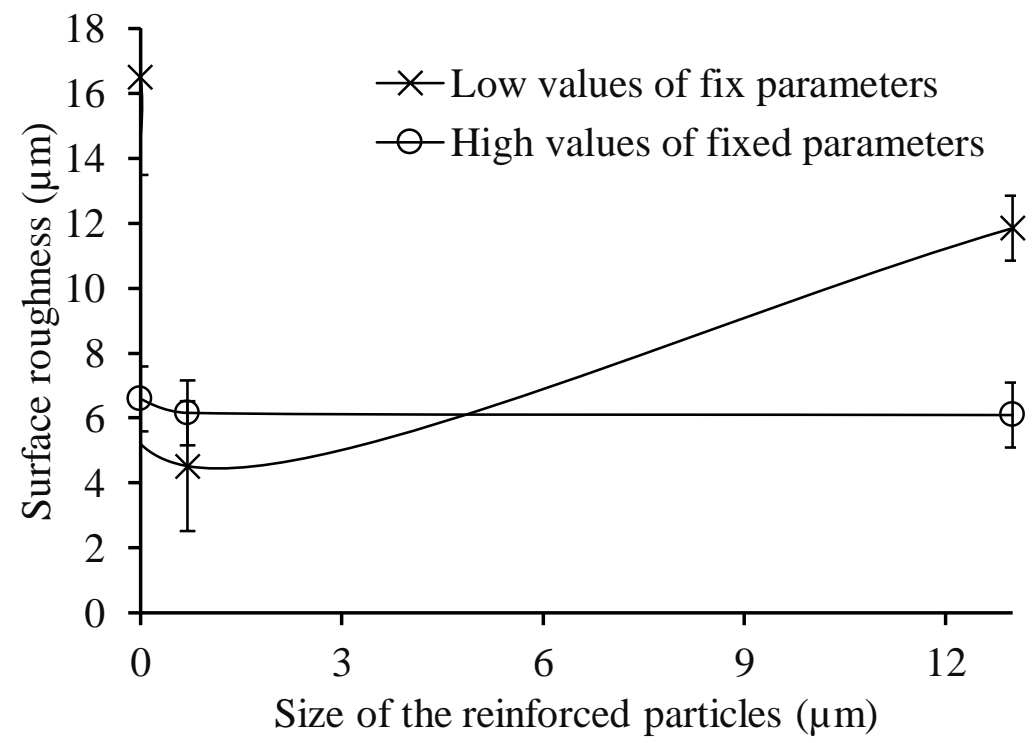

Fig. 11: Effect of reinforcing particle on surface roughness (on central hole).

\subsection{Fatigue life}

Fatigue life of the machined samples was analyzed in the way similar to that of surface roughness. Though the machining conditions don't have direct correlation with fractured surfaces, however, affects the fatigue life noticeably. The influence of feed on fatigue life at low (speed: $20 \mathrm{~m} / \mathrm{min}$ and reinforcement 0 , i.e., no particle) and high (speed: $100 \mathrm{~m} / \mathrm{min}$ and particles: $13 \mu \mathrm{m}$ ) values of fixed/ constant parameters is presented in figure 12. It shows that fatigue life of the specimens at lower values of fixed parameters is always higher than that at higher values of fixed parameters. Fatigue life of the matrix material initially reduces with the rise of feed then it rise with further rise of feed when machined at lower speed. A similar trend in fatigue life was also noticed for $13 \mu \mathrm{m}$ particle reinforced MMCs with the variation of feed and machined at higher speed. However, the rates of increase and decrease of fatigue life with variation of feed are very low in this case compare to that of samples machined at lower fixed parameters. 
The influence of speed on fatigue life at low (feed: $0.01 \mathrm{~mm} / \mathrm{rev}$ and reinforcement 0 , i.e., no particle) and high (feed: $0.03 \mathrm{~mm} / \mathrm{rev}$ and particles: $13 \mu \mathrm{m}$ ) values of fixed/ constant parameters is presented in figure 13 . It shows that fatigue life of specimens at lower values of fixed parameters is always higher than that at higher values of fixed parameters except those machined at the speed of $20 \mathrm{~m} / \mathrm{min}$. Fatigue life of matrix material decreases with the rise of feed at a lower rate when machined at lower speed. An opposite trend of fatigue life is noticed for $13 \mu \mathrm{m}$ particle reinforced MMCs with the variation of feed when machined at higher speed.

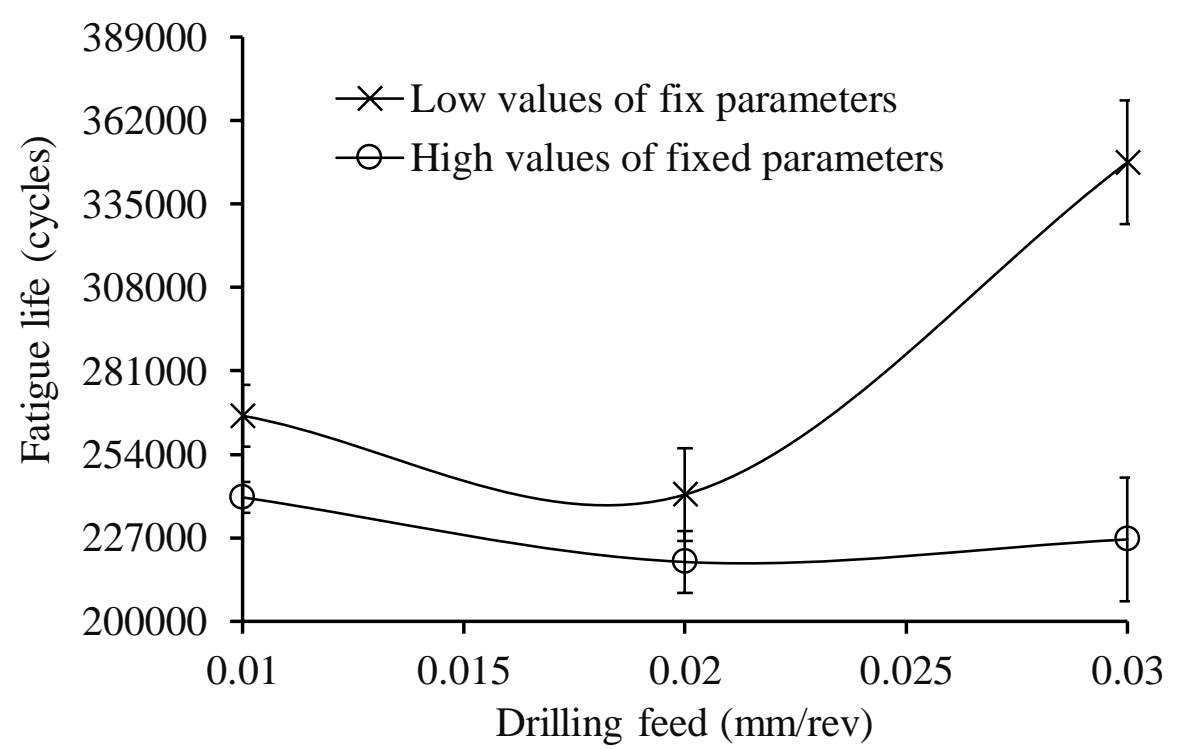

Fig. 12: Effect of feed rate on fatigue life.

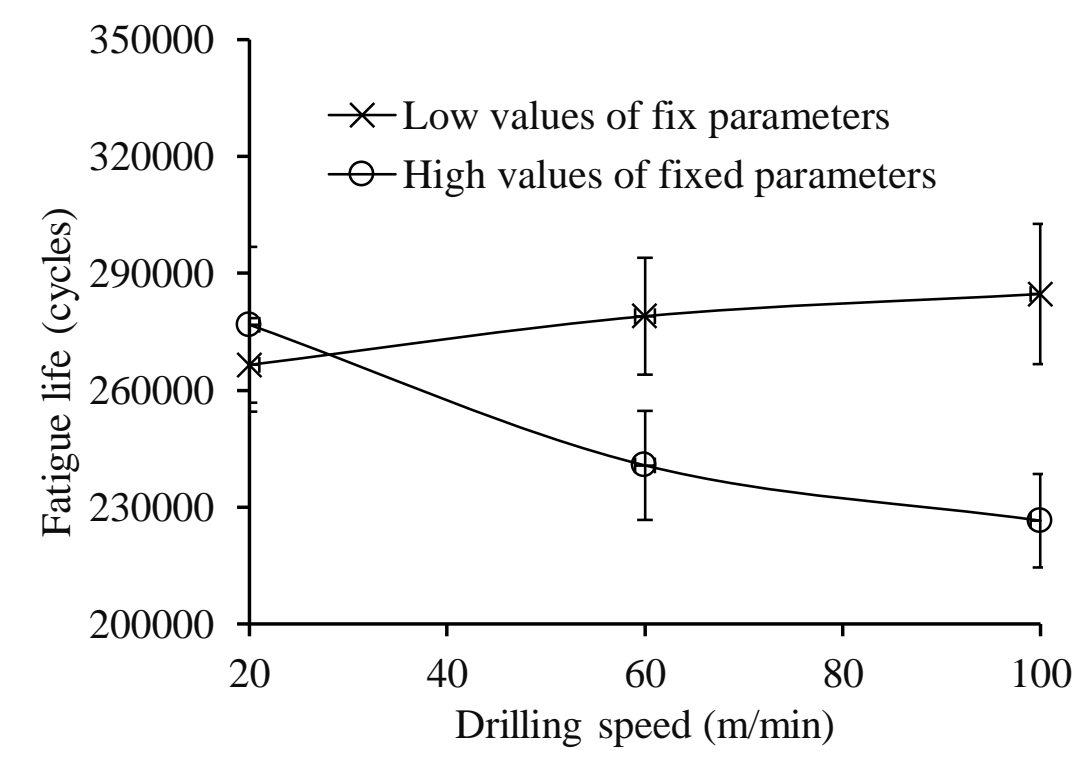

Fig. 13: Effect of drilling speed on fatigue life.

The effect of reinforced particles on fatigue life at low (speed: $20 \mathrm{~m} / \mathrm{min}$ and feed $0.01 \mathrm{~mm} / \mathrm{rev}$ ) and high (speed: $100 \mathrm{~m} / \mathrm{min}$ and feed: $0.03 \mu \mathrm{m}$ ) values of fixed/constant parameters is presented in Fig. 14. It shows that fatigue life of specimens at lower values of fixed parameters is always higher than that at higher values of fixed parameters and decreases slightly with the increase of reinforce particle size when machined at lower 
speed and feed. On the other hand, fatigue life reduces at a higher rate with the increase of reinforced particle size when those samples were machined at higher speed and feed.

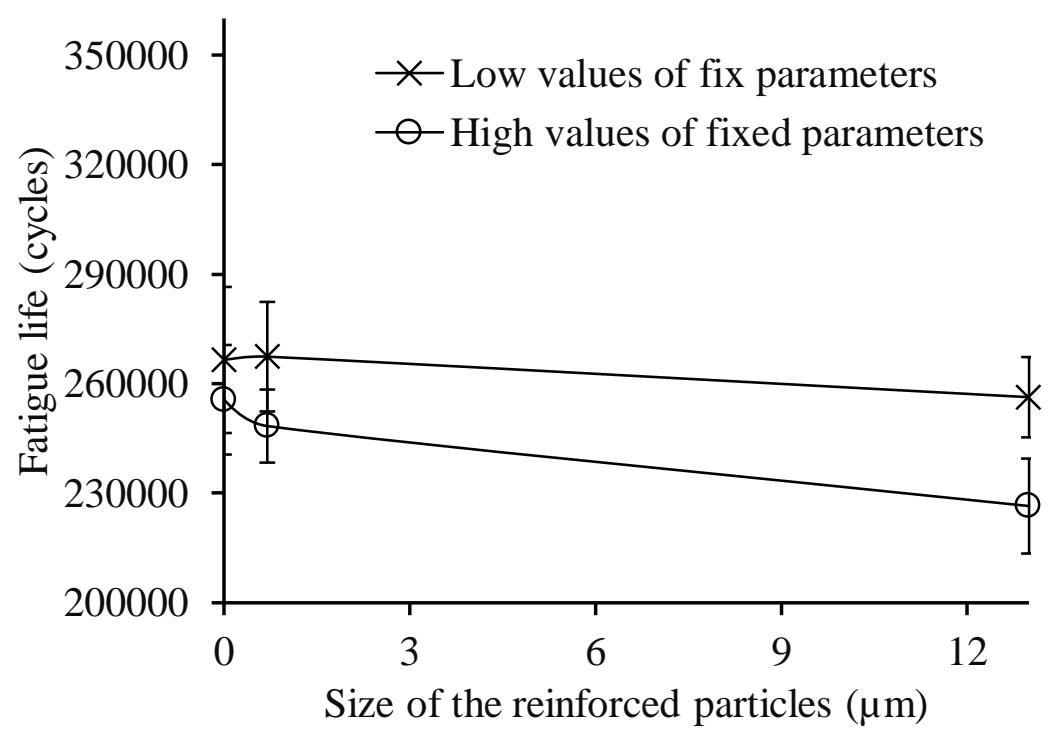

Fig. 14: Effect of reinforcement size in MMCs on fatigue life.

\subsection{Surface roughness and fatigue}

As outlined previously (section 3.2), crack propagation from fatigue does not follow the machining traces and therefore it is unlikely that the surface roughness has any effect on fatigue life for the parameters considered in this study to fabricate the specimens. The influence of surface roughness of drilled hole on fatigue life is presented in figure 15 which does not give any conclusive evidences.

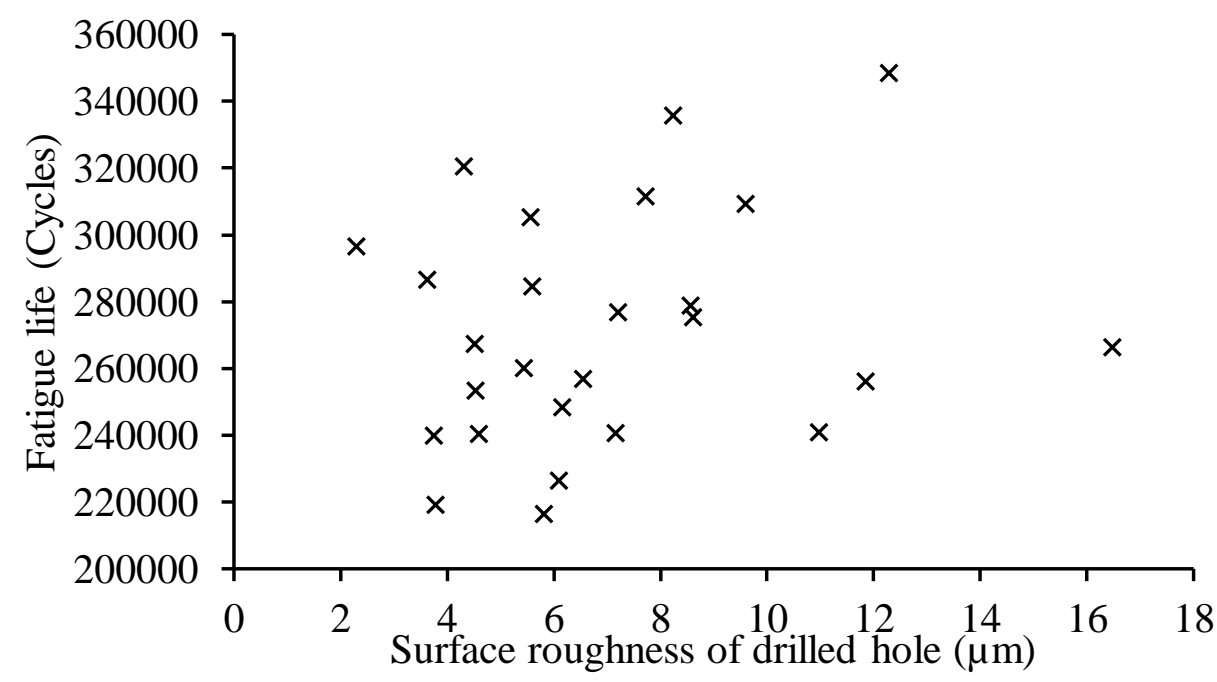

Fig. 15: Effect of surface roughness of drilled hole on fatigue life.

\section{Discussion}

Overall fatigue life involves two modules: time to start crack and time to propagate crack. In a defect free test specimens, the time to start fatigue crack inhabits a substantial portion of the entire fatigue life (Park, Crosky, \& Hellier, 2008). For example, in samples of high static strength without notch (i.e., aluminium alloys), start of crack generally inhabits 75 to $95 \%$ of the entire fatigue life (Hahn \& Simon, 1973). The portion of time 
comprised of the start of crack also rises with the rise static tensile strength. The tensile strengths of MMCs are higher than unreinforced alloys. Therefore it is expected that the fatigue life of MMCs would be predominantly controlled by the initiation of fatigue crack. These suppositions are sustained by the outcomes of a number of investigators as available in literature (Wang, Liu, Yao, He, \& Geng, 1994).

The key crack initiation is due to the development of persistent slip bands (PSBs) in unreinforced aluminium alloys (Baxter \& McKinney, 1988). Fatigue life is controlled by the development of kinetics of PSBs during low-cyclic load range in aluminium alloys hardened due to precipitation. It is usually believed that, material in PSB dearth strengthening precipitates and is considerably softer than the matrix around. Nevertheless, particle reinforced MMCs inhabit supplementary crack initiation locations as a result of particulates. Srivatsan et al. (Srivatsan, Auradkar, Prakash, \& Lavernia, 1991) recommended that the interfaces between particle and matrix are significant crack initiation locations. The mechanical mismatch between hard and brittle reinforcement, and ductile matrix material enhances the stress concentration at and near particle/matrix interfaces due to cyclic deformation. This brings about the failure of matrix prematurely or separation of the particles from the matrix. Conversely, Llorca and Poza (Llorca \& Poza, 1995) established that the fracture of particles is the leading damage mechanism under cyclic deformation where reinforcements were fractured by cracks normal to the axis of loading. In addition to this intrinsic crack initiation locations, there are extrinsic crack initiation locations for example, casting flaws, particle clusters and porosities. The susceptibility to break of particles rests on size and strength of particles. In general, larger and weaker particles more likely to fracture compare to smaller and stronger ones (Curry \& Knott, 1978) as a result of local stress concentration on the particles. Large mismatch in elastic modulus between reinforcing particles and metal matrix generates a constrained deformation in the matrix and consequently stress concentrate near the reinforcing particles. Fracture of the particles is dominant in region with large particles and clusters due to short inter-particle distance that facilitates linkage between voids and/or cracks in the particles (Srivatsan \& Al-Hajri, 2002; Srivatsan, Al-Hajri, Petraroli, Hotton, \& Lam, 2002; Srivatsan et al., 1991). Larger particles, which also have a higher chance of having critical flaw, generate high load transfer from plastically deforming aluminium matrix to elastically deforming particle, which can introduce crack initiations. On the other hand, smaller particulates generally do not crack however, the strain differences between matrix and particle cause debonding (Ceschini et al., 2006). The classic mechanism of void nucleation and formation is related to the ductile failure between metal matrix and particles, where local stress is not high enough to initiate cracks in the particles or offer de-bonding (Srivatsan \& Al-Hajri, 2002; Srivatsan et al., 2002; Srivatsan et al., 1991).

It was found that the size of reinforcing particles has the most substantial influence on fatigue life with an influence ratio $(\mathrm{P})$ of $35.41 \%$, whereas the contributions of speed and feed are 0.05 and $4.29 \%$, respectively, and considered to be non-significant factors (Pramanik, Islam, et al., 2017). The rest of the influence ration is contributed through the interactions among different parameters. Therefore interactions among different parameters with their variations are presented in the following sections. 


\subsection{Feed and fatigue}

High compressive residual stresses and high surface hardness favours longer fatigue life (Sasahara, 2005) and towards that, lower feed rate causes surface residual stress to swing towards compression, which in turn extend fatigue life. Compressive residual stresses that are ahead of crack tip are detrimental towards crack propagation. Thus, a crack that starts beneath machined surfaces might propagate until a compressive stress region is reached where the crack will be retarded. Higher feed rate generates tensile residual stress zone and therefore crack can propagate till rupture. Samples with higher compressive residual stresses on surfaces require a longer time to start and spread of cracks from the surfaces (Schwach \& Guo, 2006). Thus fatigue life increases with the increase of surface hardness due to the increase of yield strengths of surface layers as a result of work hardening. Thus work hardening and residual stress depend on each other via machining processes which can be regulated with proper selection of variables during machining process (Sasahara, 2005; Sasahara, Obikawa, \& Shirakashi, 2004). In view of that, machining of specimens with high values of fixed parameters with varying feed are justified (figure 11). However, for specimens machined with low values of fixed parameters, fatigue life increases significantly between feeds 0.02 to $0.03 \mathrm{~mm} / \mathrm{rev}$, which is unusual. It was noticed that surface roughness (figure 8) had a decreasing trend with the increase of feed rate at low values of fixed parameters. This gives the impression that material deformation mechanism is different in this case as a result of extensive material (matrix) flow at lower feed rate considered in this investigation.

\subsection{Machining speed and fatigue}

Generation of tensile residual stresses is due to thermal effects and compressive stresses is due to mechanical deformation during machining operations. Thus, higher cutting speed tends to induce tensile residual stresses on machined surfaces as a result of enhanced temperature rise close to cutting edge on machined surfaces (Navas, Gonzalo, \& Bengoetxea, 2012; Pramanik, Zhang, \& Arsecularatne, 2008). In case the local temperature rise is significant and heat conduction is limited, phase transformation due to quenching effect is likely to occur, which may facilitate compressive residual stresses generation. However, this is unlikely for the materials considered in this investigation. The influence of temperature is comparatively small at low cutting speed. With the variation of machining speed, it seems that the mechanical and thermal effects balance out and resulting mostly constant tensile residual stress on machined specimens (without any reinforcement) at low values of fixed parameters at higher machining speed. Therefore, the fatigue life of machined specimens remains constant with respect to machining speed as shown in Fig. 13. It also seems that higher speed causes higher degree of particle fracture and cracks in the machined surface which reduce fatigue life of machined specimens at high values of fixed parameters with the increase of speed.

\subsection{Reinforcing particle size and fatigue}

There are mainly three factors that are accountable for extreme mechanical deformation on machined surface that take possession of the thermal effects, namely: (a) restraint of matrix flow because of particles, (b) indentation of particles on the machined surface and (c) extreme compression of matrix in between particles 
and tool (Pramanik et al., 2008). Therefore, it is likely that machined MMCs specimens should have higher fatigue life compare to that of matrix material itself. However, the particle fracture and debonding induce huge amount of defects in the machined surface of MMCs. These cause significant reduction of fatigue life of MMCs compare to the corresponding matrix materials. Severity of machining conditions rises with higher strain and strain rate at higher feeds and speeds which induces higher degree of particle fracture and debonding in the case of MMCs. Therefore, higher fatigue life is obtained at low values of fixed parameters with the variation of reinforced particle size (Fig. 14).

\section{Conclusion}

The above investigation on the effect of machining speed and feed, and the size of reinforcement on the fatigue behaviour of MMCs can be concluded in following points.

Though the machining process leaves traces on newly generated surface, fatigue cracks don't follow those traces. Crack propagation is arrested or deflected by reinforced particles. The bigger particles possess a higher capability to stop crack propagation though those are more prone to facture. Therefore, machined MMC specimens reinforced with smaller or no particles often completely separate as opposed to the counterparts containing bigger reinforcing particles. In addition, cracks are almost straight and sharp when the particles are smaller but change the course and surface along the crake is highly damaged when the particles are bigger.

The appearance of fractured surfaces on different specimens are very similar regardless of particles size and machining conditions. Fractured surfaces were very rough with the evidence of gross ductile failure of matrix and brittle failure of reinforcing $\mathrm{SiC}$ particulates by cracking as well as de-bonding at the interfaces with matrix material. Isolated pockets of striation-like features and traces of ductile failure through the formation and presence of shallow dimples were present all over the surface.

The fatigue life of MMCs are much lower than that of corresponding matrix material in all most all cases considered in this investigation. This is due to fracture and de-bonding of particles that induce defects in machined MMCs surfaces.

Fatigue life has an initial decreasing trend with the increase of feed and then it increases significantly with further increase of feed at low values (in the absence of particles, speed $20 \mathrm{~m} / \mathrm{min}$ ) of fixed parameters but almost remains constant with the increase of feed at high values $(13 \mu \mathrm{m}$ particles, speed $100 \mathrm{~m} / \mathrm{min})$ of fixed parameters. At low values of fixed parameters, fatigue life has a slight increasing trend with the increase of speed but an opposite trend was noticed at high values of fixed parameters. The increase of reinforced particles size reduces the fatigue life of machined specimens at low and high values of fixed parameters.

\section{References}

Abrāo, A. M., \& Aspinwall, D. K. (1996). The surface integrity of turned and ground hardened bearing steel. Wear, 196(1-2), 279-284. doi:http://dx.doi.org/10.1016/0043-1648(96)06927-X 
Arsenault, R., Wang, L., \& Feng, C. (1991). Strengthening of composites due to microstructural changes in the matrix. Acta metallurgica et materialia, 39(1), 47-57.

Basak, A., Pramanik, A., \& Islam, M. N. (2013). Failure mechanisms of nanoparticle reinforced metal matrix composite. Paper presented at the Advanced Materials Research.

Baxter, W., \& McKinney, T. (1988). Growth of slip bands during fatigue of 6061-T6 aluminum. Metallurgical Transactions A, 19(1), 83-91.

Bayoumi, M. R., \& Abdellatif, A. (1995). Effect of surface finish on fatigue strength. Engineering Fracture Mechanics, 51(5), 861-870.

Callister, W. D. a. D. G. R. (2010). Materials Science and Engineering An Introduction - 8th Edition. Versailles: John Wiley \& Sons.

Ceschini, L., Minak, G., \& Morri, A. (2006). Tensile and fatigue properties of the AA6061/20vol\% Al $203 p$ and AA7005/10vol\% Al 2 O 3p composites. Composites Science and Technology, 66(2), 333-342.

Curry, D., \& Knott, J. (1978). Effects of microstructure on cleavage fracture stress in steel. Metal Science, 12(11), 511514.

Dieter, G. E. (2015). Mechanical metallurgy (3rd ed.). New York: McGraw-Hill

Hahn, C., \& Simon, R. (1973). A review of fatigue crack growth in high strength aluminum alloys and the relevant metallurgical factors. Engineering Fracture Mechanics, 5(3), 523IN1537-1536IN2540.

Hakami, F., Pramanik, A., \& Basak, A. (2016). Effect of machining on the fatigue life of steels. In J. Davim (Ed.), Metal Cutting Technologies: Progress and Current Trends (pp. 76-94). Berlin, Germany: Walter de Gruyter GmbH \& Co KG.

Hall, J. N., Jones, J. W., \& Sachdev, A. K. (1994). Particle size, volume fraction and matrix strength effects on fatigue behavior and particle fracture in 2124 aluminum-SiC $p$ composites. Materials Science and Engineering: $A$, 183(1), 69-80.

Islam, M., Anggono, J., Pramanik, A., \& Boswell, B. (2013). Effect of cooling methods on dimensional accuracy and surface finish of a turned titanium part. The International Journal of Advanced Manufacturing Technology, 69(9-12), 2711-2722.

Islam, M., Boswell, B., \& Pramanik, A. (2013). An Investigation of Dimensional Accuracy of Parts Produced by ThreeDimensional Printing. Paper presented at the Proceedings of the World Congress on Engineering.

Islam, M., \& Pramanik, A. (2015). Effects of Insert Geometry and Feed Rate on Quality Characteristics of Turned Parts. Journal of Advanced Manufacturing Systems, 14(03), 149-166.

Javidi, A., Rieger, U., \& Eichlseder, W. (2008). The effect of machining on the surface integrity and fatigue life. International Journal of Fatigue, 30(10-11), 2050-2055. doi:http://dx.doi.org/10.1016/j.ijfatigue.2008.01.005

Karlak, R., Crossman, F., Grant, J., Fleck, J., \& Mehan, R. (1974). Failure Modes in Composites-II. Paper presented at the AIME Symp. Proc., The Minerals, Metals and Materials Society, Warrendale, PA.

Koster, W. P. F., M. ; Kahles, J. F. ; Fritz, L. J. ; Gatto, L. R. (1970). Surface Integrity of Machined Structural Components. Retrieved from

Kumai, S., King, J. E., \& Knott, J. F. (1990). Short and long fatigue crack growth in a SiC reinforced aluminium alloy. Fatigue \& Fracture of Engineering Materials \& Structures, 13(5), 511-524.

Li, W., Liang, H., Chen, J., Zhu, S., \& Chen, Y. (2014). Effect of SiC particles on fatigue crack growth behavior of SiC particulate-reinforced Al-Si alloy composites produced by spray forming. Procedia Materials Science, 3, 16941699.

Llorca, J., \& Poza, P. (1995). Influence of reinforcement fracture on the cyclic stress-strain curve of metal-matrix composites. Acta metallurgica et materialia, 43(11), 3959-3969.

Luk, M., Mirza, F., Chen, D., Ni, D., Xiao, B., \& Ma, Z. (2015). Low cycle fatigue of SiCp reinforced AA2009 composites. Materials \& Design (1980-2015), 66, 274-283.

Matsumoto, Y., Magda, D., Hoeppner, D. W., \& Kim, T. Y. (1991). Effect of Machining Processes on the Fatigue Strength of Hardened AISI 4340 Steel. Journal of Manufacturing Science and Engineering, 113(2), 154-159. doi:10.1115/1.2899672

Navas, V. G., Gonzalo, O., \& Bengoetxea, I. (2012). Effect of cutting parameters in the surface residual stresses generated by turning in AISI 4340 steel. International Journal of Machine Tools and Manufacture, 61, 48-57.

Novovic, D., Dewes, R., Aspinwall, D., Voice, W., \& Bowen, P. (2004). The effect of machined topography and integrity on fatigue life. International Journal of Machine Tools and Manufacture, 44(2), 125-134.

Orr, J., \& Brown, D. (1974). Elasto-plastic solution for a cylindrical inclusion in plane strain. Engineering Fracture Mechanics, 6(2), 261-274. 
Paknia, A., Pramanik, A., Dixit, A., \& Chattopadhyaya, S. (2016). Effect of Size, Content and Shape of Reinforcements on the Behavior of Metal Matrix Composites (MMCs) Under Tension. Journal of Materials Engineering and Performance, 25(10), 4444-4459.

Park, B., Crosky, A., \& Hellier, A. (2008). High cycle fatigue behaviour of microsphere Al 20 3-Al particulate metal matrix composites. Composites Part B: Engineering, 39(7), 1257-1269.

Pramanik, A., Basak, A., Islam, M. N., \& Littlefair, G. (2015). Electrical discharge machining of 6061 aluminium alloy. Transactions of nonferrous metals society of China, 25(9), 2866-2874.

Pramanik, A., Dixit, A., Chattopadhyaya, S., Uddin, M., Dong, Y., Basak, A., \& Littlefair, G. (2017). Fatigue life of machined components- a review Advances in Manufacturing. doi:10.1007/s40436-016-0168-z

Pramanik, A., Islam, M., Davies, I., Boswell, B., Basak, A., \& Dong, Y. (2017). Contribution of machining to the fatigue behaviour of metal matrix composites (MMCs) of varying reinforcement size. International Journal of fatigue. doi:10.1016/j.jijatigue.2017.04.018

Pramanik, A., Zhang, L., \& Arsecularatne, J. (2008). Machining of metal matrix composites: effect of ceramic particles on residual stress, surface roughness and chip formation. International Journal of Machine Tools and Manufacture, 48(15), 1613-1625.

Reed, E. C., \& Viens, J. A. (1960). The Influence of Surface Residual Stress on Fatigue Limit of Titanium. Journal of Manufacturing Science and Engineering, 82(1), 76-78. doi:10.1115/1.3663004

Sasahara, H. (2005). The effect on fatigue life of residual stress and surface hardness resulting from different cutting conditions of $0.45 \% \mathrm{C}$ steel. International Journal of Machine Tools and Manufacture, 45(2), 131-136.

Sasahara, H., Obikawa, T., \& Shirakashi, T. (2004). Prediction model of surface residual stress within a machined surface by combining two orthogonal plane models. International Journal of Machine Tools and Manufacture, 44(7), 815-822.

Schwach, D. W., \& Guo, Y. (2006). A fundamental study on the impact of surface integrity by hard turning on rolling contact fatigue. International Journal of fatigue, 28(12), 1838-1844.

Shang, J. K., Yu, W., \& Ritchie, R. (1988). Role of silicon carbide particles in fatigue crack growth in SiC-particulatereinforced aluminum alloy composites. Materials Science and Engineering: A, 102(2), 181-192.

Sharman, A. R. C., Aspinwall, D. K., Dewes, R. C., Clifton, D., \& Bowen, P. (2001). The effects of machined workpiece surface integrity on the fatigue life of $\gamma$-titanium aluminide. International Journal of Machine Tools and Manufacture, 41(11), 1681-1685. doi:http://dx.doi.org/10.1016/S0890-6955(01)00034-7

Srivatsan, T., \& Al-Hajri, M. (2002). The fatigue and final fracture behavior of SiC particle reinforced 7034 aluminum matrix composites. Composites Part B: Engineering, 33(5), 391-404.

Srivatsan, T., Al-Hajri, M., Petraroli, M., Hotton, B., \& Lam, P. (2002). Influence of silicon carbide particulate reinforcement on quasi static and cyclic fatigue fracture behavior of 6061 aluminum alloy composites. Materials Science and Engineering: A, 325(1), 202-214.

Srivatsan, T., Auradkar, R., Prakash, A., \& Lavernia, E. (1991). Influence of Microstructure on Cyclic Stress Response and Cyclic Fracture Behavior of Aluminium Alloy Metal-Matrix Composite Fracture of Engineering Materials and Structures (pp. 194-202): Springer.

Sugimura, Y., \& Suresh, S. (1992). Effects of sic content on fatigue crack growth in Aluminum Alloys Reinforced with SiC Particles. Metallurgical and Materials Transactions A, 23(8), 2231-2242.

Taylor, D., \& Clancy, O. M. (1991). The Fatigue performance of Machined surfaces. Fatigue \& Fracture of Engineering Materials \& Structures, 14(2-3), 329-336. doi:10.1111/j.1460-2695.1991.tb00662.x

Tirosh, J., Katz, E., Lifschuetz, G., \& Tetelman, A. (1979). The role of fibrous reinforcements well bonded or partially debonded on the transverse strength of composite materials. Engineering Fracture Mechanics, 12(2), 267277.

Wang, D., Liu, J., Yao, C., He, Z., \& Geng, L. (1994). The initiation of fatigue microcracks near SiC whisker ends in a silicon carbide whisker reinforced 6061 aluminium composite. Journal of materials science letters, 13(13), 957-959. 